SHORT REPORT

\title{
Rapidly progressive dementia syndrome associated with a novel four extra repeat mutation in the prion protein gene
}

\author{
C Yanagihara, M Yasuda, K Maeda, K Miyoshi, Y Nishimura
}

J Neurol Neurosurg Psychiatry 2002;72:788-791

\begin{abstract}
Objective: To gain a better understanding of how mutations of the prion protein $(\operatorname{PrP})$ gene are responsible for progressive dementia syndrome and to clarify the correlation between genotype and phenotype, which should help to explain how the prion promotes neurological symptoms.

Background: Genetic prion diseases are associated with point or insertional mutations in the $\operatorname{PrP}$ gene. The insertional mutations described so far consist of one to nine extra octapeptide repeats, except three repeats. Insertions of one to four extra octapeptide repeats cause CreutzfeldtJakob disease (CJD) in patients without a family history of neurological disorders. CJD generally presents as progressive dementia.

Methods: Routine clinical assessment and sequence analysis of the PrP gene of DNA from a 56 year old Japanese man with progressive dementia syndrome.

Results: Sequence analysis disclosed a novel four octapeptide repeat insertion within the PrP gene. The patient was initially affected by progressive cerebellar and brainstem signs; a few months later myoclonus and rapidly progressive dementia appeared. These symptoms were similar to those of sporadic CJD.

Conclusion: Taken together with previous investigations of CJD patients with insertional mutations, the current observation strengthens the notion that small octapeptide insertions from one to four extra repeats within the PrP gene cause CJD, which is characterised by late onset after the sixth decade, rapid progression, death within a few months, and lack of a family history of neurological disorders, the latter suggesting incomplete penetrance. Different patients with four extra octapeptide repeats have different patterns of extra insertions, suggesting that progression of the disease depends on the number of extra repeats.
\end{abstract}

$\mathrm{H}$ uman prion diseases are rare neurodegenerative disorders associated with spongiform degeneration of the central nervous system. They are caused by a type of protein called a prion. The harmless and infectious forms of the prion protein are nearly identical, except that the infectious form has a different folded shape. There are three major categories of prion disease: sporadic, hereditary, and acquired. The genetic prion diseases account for about $10 \%$ of all cases and are associated with point or insertional mutations in the prion protein (PrP) gene on chromosome 20. The insertional mutations as well as point mutations give rise to an abnormally folded isoform of the prion protein, therefore the hereditary prion diseases share a common pathway of neurodegeneration with the infectious form. ${ }^{12}$

The insertional mutations described so far consist of one to nine (but not three) extra octapeptide repeats, between codons 51 and 91 of the PrP gene. ${ }^{3-16}$ This region normally comprises one nonapeptide (R1) followed by four octapeptides (R2, R2, R3, R4), which have the same amino acid sequence but can be distinguished by variations in DNA sequence. Reports of five to nine extra octapeptide repeats indicate an autosomal dominant pattern of inheritance and a considerably heterogeneous phenotype of prion diseases. ${ }^{8-16}$ Conversely, small octapeptide insertions of one, two, or four extra repeats usually present as classic Creutzfeldt-Jakob disease (CJD). Patients with these types of mutation usually lack a family history of neurological disorders. ${ }^{3-7}$

In this study we describe a patient who carried new in frame inserts of four octapeptide repeats within the PrP gene. The disease began with cerebellar and brainstem signs in his sixth decade and progressed rapidly, accompanied by myoclonus and progressive dementia. We report details of the clinical and genetic data and discuss the genotype/phenotype correlation.

\section{CASE REPORT}

A 56 year old Japanese man presented with rapidly progressive cerebellar ataxia and myoclonus. The patient's father had experienced no neurological problems until he died from cerebral infarction at the age of 82 . The patient's mother showed mild depression at the age of 77 after her husband's death. A computed tomography scan of her brain showed no abnormal findings. She died from chronic heart failure at the age of 78. The siblings of the parents and their descendants had no history of dementia (obtained by informant based interview). The patient himself had four siblings aged 55-68 and two children aged 23 and 30, all living and well. Therefore, there was no family history of dementia. The patient was well until three months before admission. He complained of general fatigue and back pain in April 2000. One month later, at the end of May, he noticed image distortion and actual impairment of visual acuity. Late in June, gait disturbance had appeared and he could not walk straight. Three weeks later his left hand began to shake when he tried to move it. At this time he consulted a doctor and was diagnosed as having dysarthria, ataxic gait, and left dominant cerebellar sign. Magnetic resonance imaging of the brain showed moderate cerebellar atrophy. He became delirious at night. In a few days, gait disturbance had progressed and he became wheel chair dependent. Spontaneous speech had decreased, and he spoke only when spoken to. In a week, at the beginning of August myoclonus appeared in the legs. Electroencephalography (EEG) showed diffuse high amplitude slow waves. He was referred to our hospital on 8 August 2000. The neurological

Abbreviations: CJD, Creutzfeldt-Jakob disease; EEG electroencephalography; PCR, polymerase chain reaction 


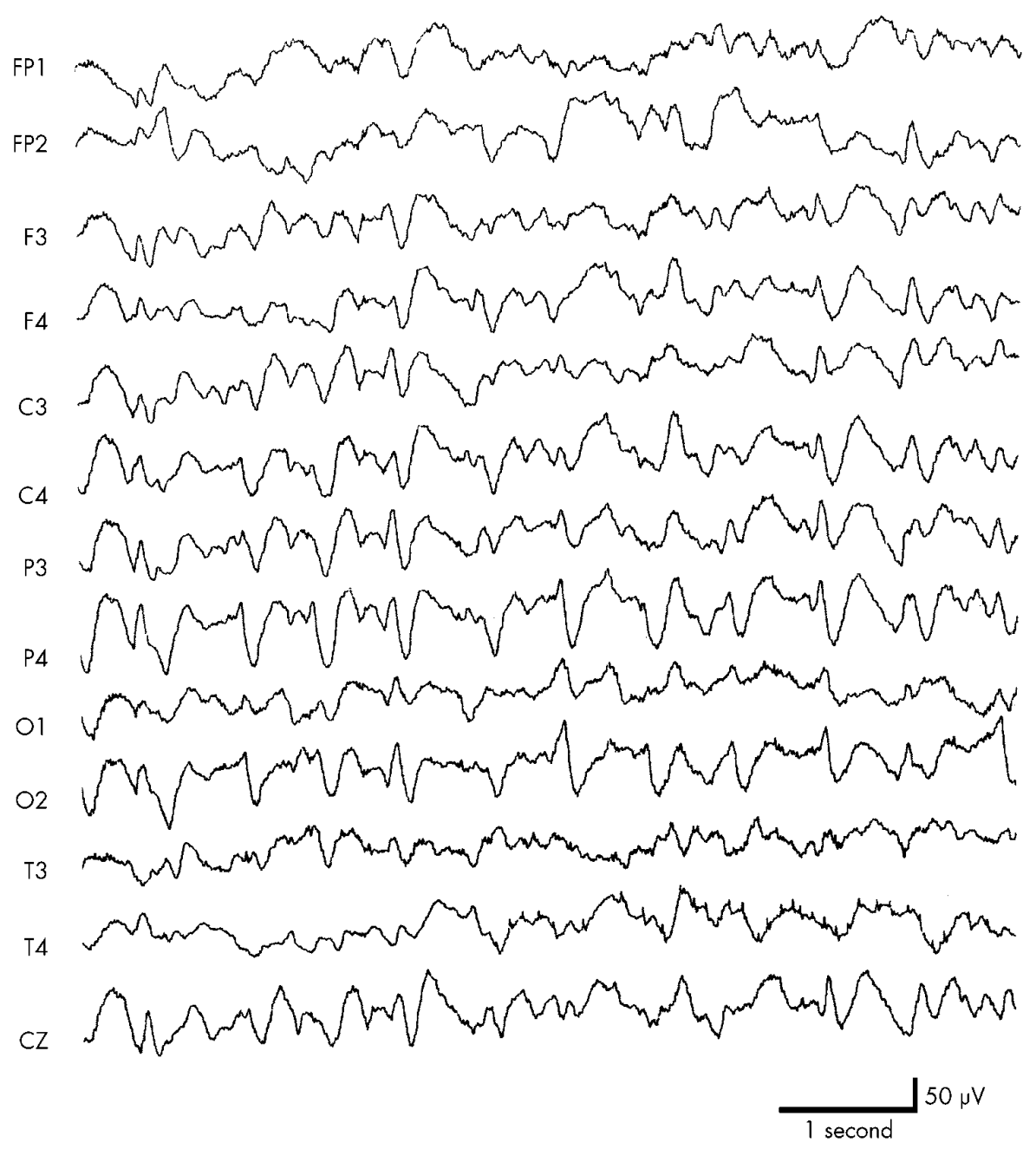

Figure 1 Electroencephalogram showing diffuse periodic synchronised discharge.

examination showed decreased spontaneous speech and myoclonus in all extremities. Muscle tonus was increased. Deep tendon reflexes were increased in the lower extremities with a positive Babinski sign. His symptoms had progressed rapidly in a few days and he opened his eyes only when he was spoken to. Startle reactions induced by small sounds or weak stimuli were observed. On 12 August, he developed dysphagia, constant slight high fever, and sleep apnoea. At this point, EEG showed diffuse periodic synchronised discharge (fig l). In the left arm, myoclonus decreased and decorticate rigidity was observed, which extended to both arms in a few days. Fever persisted, but laboratory examinations excluded an infectious cause. The symptoms progressively worsened during the next few weeks. He became comatose with irregular breathing and severe apnoea. Two months after admission, the patient died from respiratory failure. Autopsy was not allowed.

\section{GENE ANALYSIS}

After written informed consent had been obtained from a family member, genomic DNA was extracted from peripheral blood leucocytes of the patient. A similar sample was taken from a normal control with informed consent. The target PrP gene whose product harbours exon 1 was amplified by the polymerase chain reaction (PCR). The PCR product from the DNA of a normal subject showed one major band on agarose gel electrophoresis. The DNA of the patient had a band of the same size and also another larger band. To sequence the two bands separately, they were excised separately and purified.
The resulting DNAs were ligated with the vector pCR2.1 supplied with the TA Cloning kit following the manufacturer's protocol (Invitrogen, Groningen, The Netherlands). Plasmid DNA from five positive clones was isolated by the alkaline lysis mini prep method, purified, and completely sequenced (both alleles) by using a BigDye terminator sequencing kit and an ABI310 genetic analyser (Perkin-Elmer Applied Biosystems). Sequencing of the fragments showed that the larger fragment had nine repeats ( R1 -R2 -R2 -R2 -R3 -R2 -R2 -R3 -R4) including four extra repeats ( $R 2-R 3-R 2-R 2)$, whereas the smaller fragment had the normal five repeats (R1 -R2 -R2 -R3 -R4) (fig 2). Sequencing of the whole coding region of the PrP gene ruled out the presence of other mutations and polymorphism. The common methionine/valine polymorphism at codon 129 of the PrP gene may influence the CJD phenotype. On the mutant allele of the patient, 32 extra codons were inserted in the repeat region, so that codon 161 on the mutant allele corresponds to codon 129 on the normal allele. Codon 129 on the normal allele and codon 161 on the mutant allele were both methionine.

\section{DISCUSSION}

In the presenting case, visual disturbance was an initial symptom, and soon cerebellar and pyramidal signs, myoclonus, dementia, and periodic synchronised discharge in the EEG appeared. A neuropathological examination was not carried out, but the clinical course followed the typical rapid progression of CJD. Sequence analysis showed a novel four octapeptide repeat insertion within the PrP gene, the order of 

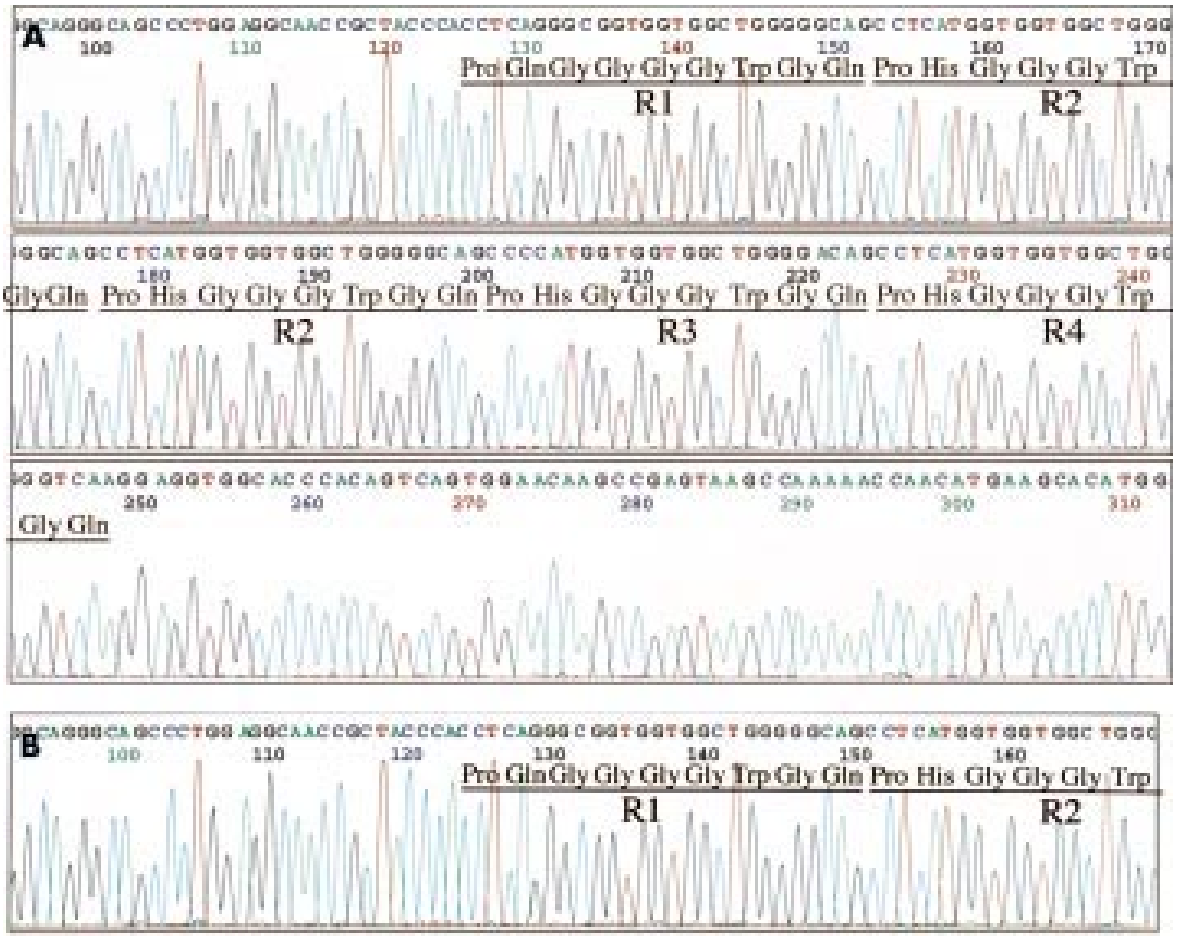

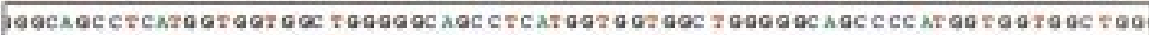
GlyGin Pro His Gly Gly Gly Tro Gly Gin Pro His Gly Gily Gly Trp Gly Gin Pro His Gily Gly Gly Trp

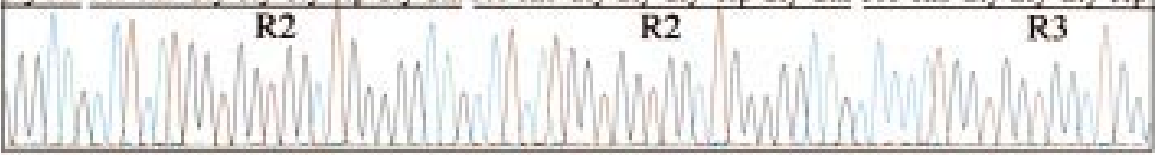

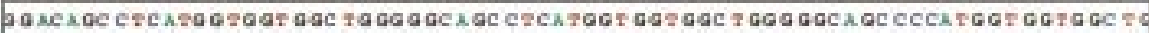

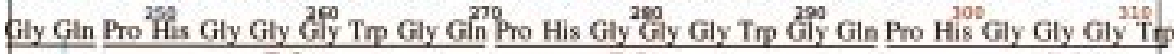

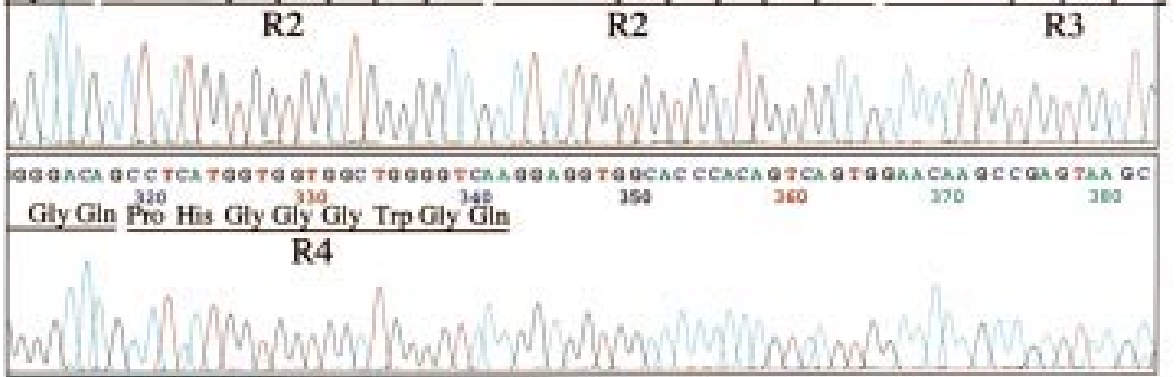

Figure 2 Sequence analysis of prion protein gene polymerase chain reaction products from the patient. The tandem repeat region from the fragment of expected size $(A)$ contained $114 \mathrm{bp}$, the amino acid sequence of which included five peptide repeats, R1 -R2 -R2 -R3 -R4. The tandem repeat region from the larger fragment (B) contained 210 bp and comprised nine peptide repeats, R1 -R2 -R2 -R2 -R3 -R2 -R2 -R3 -R4 Repeats are named according to the nomenclature proposed by Goldfarb et al. ${ }^{\circ}$

which is different from that of all reported cases of four extra insertions (table 1). Four of six cases with four extra octapeptide repeats, including the presenting case, had a progressive course accompanied by a cerebellar sign, myoclonus, and dementia, which are similar to sporadic CJD. Exceptionally, one case reported by Isozaki et $a l^{7}$ had initial symptoms of

Table 1 Studies of cases of prion disease with four extra octapeptide repeats

\begin{tabular}{|c|c|c|c|c|c|c|}
\hline Reference & $\begin{array}{l}\text { Age at } \\
\text { onset/sex }\end{array}$ & $\begin{array}{l}\text { Family } \\
\text { history }\end{array}$ & $\begin{array}{l}\text { Duration } \\
\text { of illness }\end{array}$ & Clinical features & Spongiform & Order of octarepeats \\
\hline Goldfarb et al. ${ }^{6}$ & - & - & - & Neurologically normal, liver cirrhosis & - & R1, R2, R2, R3, R2, R3, R2, R3, R4 \\
\hline Campbell et al. ${ }^{4}$ & $56 / M$ & - & 8 weeks & Confusion, cerebellar sign, myoclonus & + & $R 1, R 2, R 2, R 2, R 2, R 2, R 2, R 3, R 4$ \\
\hline Laplanche et al. ${ }^{5}$ & $82 / F$ & - & 4 months & Pyramidal sign, myoclonus & ND & $\mathrm{R} 1, \mathrm{R} 2, \mathrm{R} 2, \mathrm{R} 3, \mathrm{R} 2, \mathrm{R} 2, \mathrm{R} 2, \mathrm{R} 3, \mathrm{R} 4$ \\
\hline Rossi et al. ${ }^{3}$ & $65 / M$ & $-^{*}$ & 6 months & Cerebellar sign, pyramidal sign, myoclonus & + & $R 1, R 2, R 2, R 3 g, R 2, R 3 g, R 2, R 3, R 4$ \\
\hline Isozaki et aP. & $62 / M$ & - & 7 years & Slowly progressive dementia, extrapyramidal sign & ++ & $\mathrm{R} 1, \mathrm{R} 2, \mathrm{R} 2, \mathrm{R} 2, \mathrm{R} 2, \mathrm{R} 2, \mathrm{R} 2, \mathrm{R} 3, \mathrm{R} 4$ \\
\hline Our case & $56 / M$ & - & 5 months & Cerebellar sign, myoclonus, pyramidal sign & ND & $\mathrm{R} 1, \mathrm{R} 2, \mathrm{R} 2, \mathrm{R} 2, \mathrm{R} 3, \mathrm{R} 2, \mathrm{R} 2, \mathrm{R} 3, \mathrm{R} 4$ \\
\hline
\end{tabular}

Wild type of repeats: R1, R2, R2, R3, R4. Repeats are named according to the nomenclature proposed by Goldfarb et al.

*His healthy sister had the same octapeptide insertion.

ND, Not examined. 
frontal lobe dementia and long duration of illness. One case reported by Goldfarb et al $l^{6}$ involved a 63 year old subject without any neurological symptoms despite having a four octapeptide repeat insertion. Another notable finding is that all the reported patients with insertional mutations of four extra octapeptide repeats had no family history of neurological disorders. In addition, Rossi et $a l^{3}$ reported that a CJD patient with a four extra octapeptide repeat mutation had a healthy sister who had the same mutation. These results suggest incomplete penetrance of the extra four octapeptide repeat insertional mutation of the PrP gene.

As there have been only a few reports of extra insertions, it is difficult to correlate the number of extra octapeptide repeats with the clinical course. However, this case strengthens the notion that most patients with one to four extra repeats experience symptoms after the sixth decade and rapid disease progression, and usually die within a few months, although some cases of patients with short extra repeats who suffered from slowly progressive dementia have been reported. ${ }^{7-9}$ In contrast, the previous studies indicated that almost all the patients with five or more extra repeats had a long illness, beginning at an early age, mostly between the third and fourth decades of life. These facts suggest that insertional mutations of less than five extra repeats may be characterised by causing a rapidly progressive clinical course and by having a variety of symptoms.

Several lines of evidence from genetically engineered mice suggest a role for the octapeptide repeats of the PrP gene. PrP knockout mice do not make PrP and are resistant to prion disease. Introduction of a PrP transgene into PrP knockout mice restores susceptibility to prion disease. ${ }^{17}$ PrP knockout mice overexpressing truncated PrP transgenes with only one of the five octapeptide repeats also replicated infectious agent and developed the disease. ${ }^{17}$ PrP knockout mice overexpressing truncated PrP transgenes without any of the five octapeptide repeats still became diseased, but the number of days it took for symptoms to appear was greater. ${ }^{18}$ PrP transgenic mice that expressed the mouse homologue of a mutant human PrP containing a nine octapeptide insertion exhibited a slowly progressive neurological disorder that mimicked an inherited human prion disorder. ${ }^{19}$ In cultured mouse cells expressing hamster PrP that contained various numbers of octapeptide repeats, as the number of repeats increased so did the aggregation and proteinase $\mathrm{K}$ resistance of the mutant PrP protein. ${ }^{20}$ These experimental data are consistent with the notion that CJD associated with insertional mutations of the PrP gene has incomplete penetrance, a variable clinical course, an inverse correlation between the number of octapeptide repeats and the age of onset, and a positive correlation between the number of octapeptide repeats and the rate of progression of the disease. These results indicate that the region comprising the octapeptide repeats may not be essential for mediation of pathogenesis, but promotes either PrP self aggregation or aggregation between PrP and other cell factors, or modulates the extent of prion replication and disease presentation. The mechanism by which extra copies of the octapeptide repeats are inserted into the PrP gene and promote the clinical course is not known. Further studies involving additional cases are needed to determine the relation between the extra insertions in the PrP gene and clinical symptoms.

\section{ACKNOWLEDGEMENTS}

We thank M Obana for excellent technical assistance.

\section{Authors' affiliations}

C Yanagihara, Y Nishimura, Department of Neurology, Nishi-Kobe Medical Center, Kobe 651-2273, Japan

M Yasuda, K Miyoshi, Hyogo Institute for Aging Brain and Cognitive Disorders, Himeji 670-0981, Japan

K Maeda, Department of Psychiatry and Neurology, Kobe University School of Medicine, Kobe 650-0017, Japan

Correspondence to: Dr Yanagihara, Department of Neurology Nishi-Kobe Medical Center, 5-7-1 Kojidai, Nishi-ku, Kobe 651-2273, Japan; chiey@mta.biglobe.ne.jp

Received 8 August 2001

In revised form 19 November 2001

Accepted 14 December 2001

\section{REFERENCES}

1 Hegde RS, Tremblay P, Groth D, et al. Transmissible and genetic prion diseases share a common pathway of neurodegeneration. Nature 1999;402:822-6.

2 Liu JJ, Lindquist S. Oligopeptide-repeat expansions modulate protein-only' inheritance in yeast. Nature 1999;400:573-6.

3 Rossi G, Giampaolo L, lussich S, et al. Creutzfeldt-Jakob disease with a novel four extra-repeat insertional mutation in the PrP gene. Neurology 2000;55:405-10.

4 Campbell TA, Palmer MS, Will RG, et al. A prion disease with a novel 96-base pair insertional mutation in the prion protein gene. Neurology 1996;46:761-6.

5 Laplanche JL, Delasnerie-Lauprêtre N, Brandel JP, et al. Two novel insertions in the prion protein gene in patients with late-onset dementia. Hum Mol Genet 1995;4:1109-11

6 Goldfarb LG, Brown P, McCombie WR, et al. Transmissible familial Creutzfeldt-Jakob disease associated with five, seven, and eight extra octapeptide coding repeats in the PRNP gene. Proc Natl Acad Sci USA 1991;88:10926-30.

7 Isozaki E, Miyamoto K, Kagamihara Y, et al. Creutzfeldt-Jakob disease presenting as frontal lobe dementia associated with a 96 base pair insertion in the prion protein gene. (In Japanese.) Dementia 1994;8:363-71.

8 Goldfarb LG, Brown P, Little BW, et al. A new (two-repeat) octapeptide coding insert mutation in Creutzfeldt-Jakob disease. Neurology 1993;43:2392-4

9 van Harten B, van Gool WA, van Langen IM, et al. A new mutation in the prion protein gene: a patient with dementia and white matter changes. Neurology 2000;55:1055-7.

10 Cochran EJ, Bennett DA, Cervenáková L, et al. Familial Creutzfeldt-Jakob disease with a five-repeat octapeptide insert mutation. Neurology 1996;47:727-33.

11 Skworc KH, Windl O, Schulz-Schaeffer WJ, et al. Familial Creutzfeldt-Jakob disease with a novel 120-bp insertion in the prion protein gene. Ann Neurol 1999;46:693-700.

12 Nicholl D, Windl O, de Silva R, et al. Inherited Creutzfeldt-Jakob disease in a British family associated with a novel 144 base pair insertion of the prion protein gene. J Neurol Neurosurg Psychiatry 1995;58:65-9

13 Capellari S, Vital C, Parchi P, et al. Familial prion disease with a novel 144-bp insertion in the prion protein gene in a Basque family. Neurology 1997;49:133-41.

14 van Gool WA, Hensels GW, Hoogerwaard EM, et al. Hypokinesia and presenile dementia in a Dutch family with a novel insertion in the prion protein gene. Brain 1995;118:1565-71.

15 Owen F, Poulter M, Collinge J, et al. A dementing illness associated with a novel insertion in the prion protein gene. Mol Brain Res 1992; 13:155-7.

16 Krasemann S, Zerr I, Weber T, et al. Prion disease associated with a novel nine octapeptide repeat insertion in the PRNP gene. Mol Brain Res 1995;34:173-6.

17 Fischer $M$, Rulicke T, Raeber $A$, et al. Prion protein $(\operatorname{PrP})$ with amino-proximal deletions restoring susceptibility of PrP knockout mice to scrapie. EMBO J 1996;15:1255-64.

18 Flechsig E, Shmerling D, Hegyi I, et al. Prion protein devoid of the octapeptide repeat region restores susceptibility to scrapie in PrP knockout mice. Neuron 2000;27:399-408

19 Chiesa R, Piccardo P, Ghetti B, et al. Neurological illness in transgenic mice expressing a prion protein with an insertional mutation. Neuron 1998;21:1339-51.

20 Priola SA, Chesebro B. Abnormal properties of prion protein with insertional mutations in different cell types. J Biol Chem 1998;273: 1 1980-5. 